\title{
Mídia e representação política feminina: hipóteses de pesquisa
}

\begin{tabular}{c}
\hline \hline Luis Felipe Miguel \\
Instituto de Ciência Política \\
Universidade de Brasília \\
Flávia Biroli \\
Instituto de Ciência Política \\
Universidade de Brasília \\
\hline \hline
\end{tabular}

\begin{abstract}
Resumo: $O$ artigo delineia as hipóteses centrais de uma ampla pesquisa empírica em andamento, que busca entender a confluência entre gênero, mídia e representação política. Trata-se de analisar a presença e atuação de mulheres no campo político e sua presença nos meios de comunicação de massa, no Brasil, buscando entender as relações que se estabelecem entre essas esferas no que diz respeito, especificamente, à representação política de mulheres. Em cada uma dessas esferas, existem mecanismos que restringem não só a presença de mulheres na política como também as formas que tal presença assume. Assim, o artigo procura avançar na discussão sobre de que maneira a permanência de estereótipos de gênero constrange tanto a ação política das mulheres quanto a visibilidade desta ação no noticiário jornalístico, num processo que se realimenta.
\end{abstract}

Palavras-chave: mídia; gênero; representação política; campo político

Abstract: The present article discusses central hypothesis that guide a large empirical research, still under development, about the intersections of gender, media and political representation. Analysing the presence and acting of women in the political field and their presence in the media, in Brazil, the study aims to understand the relationships between those spheres concerning the problems related to the representation of women in politics. In the field of politics and in the media, we can find mechanisms that limit not only the presence of women but also the configurations of that presence. Thus, the article discusses how the remaining of gender stereotypes limits women's political action and its visibility in the news, in a process in which one of these terms feeds back the other.

Keywords: media; gender; political representation; political field 
Os meios de comunicação de massa cumprem um papel crucial na conformação do ambiente social contemporâneo ${ }^{1}$. Eles reconfiguraram a gestão do tempo cotidiano e as fronteiras entre diferentes espaços sociais, determinados por sexo ou faixa etária; modificaram o exercício da autoridade e fragmentaram as representações mentais do mundo de que se servem as pessoas para nele se situarem (MEYROWITZ, 1985). Seu impacto na vida política é indiscutível, alterando as formas do discurso, a relação entre representantes e representados, as vias de acesso para a carreira política (THOMPSON, 1995; MIGUEL, 2002; GOMES, 2004). Ao mesmo tempo, a mídia reforça a definição dominante sobre o que é a política e quem participa legitimamente do campo - o que inclui a naturalização do viés de gênero nele presente.

Este artigo discute as hipóteses e pressupostos teóricos centrais de uma ampla pesquisa empírica, ainda em andamento, que se estabelece na confluência entre esses três temas: gênero, política e mídia. Embora haja tradição consolidada de trabalho acadêmico para cada um dos pares de temas (investigações sobre gênero e política, sobre política e mídia, sobre gênero e mídia), a interseção das três temáticas ainda é um campo pouco estudado, na literatura internacional e no Brasil.

O objetivo central da pesquisa é analisar aspectos relevantes da presença e atuação, no Brasil, de mulheres no legislativo federal e da sua presença nos meios de comunicação de massa, buscando entender as relações que se estabelecem entre essas esferas no que diz respeito, à representação política. Busca observar, assim, os mecanismos que, em cada uma dessas esferas, e de modo complementar, funcionam de modo a restringir não só a presença de mulheres no campo político como também as formas que tal presença assume. Dessa forma avança na discussão sobre de que maneira a permanência de estereótipos de gênero constrange tanto a ação política das mulheres quanto a visibilidade desta ação no noticiário jornalístico, num processo que se realimenta. Como se verá adiante, não se trata de uma relação causal, mas de práticas e mecanismos complementares que compõem, de modo significativo, processos mais amplos que definem as restrições e constrangimentos citados.

A abordagem teórica incorpora o conceito de campo político, no sentido proposto pelo sociólogo francês Pierre Bourdieu, entendendo que a mera presença no parlamento não representa capacidade igual de influência na elaboração da lei, na formulação de políticas e na produção das representações do mundo social. 0 campo é uma estrutura hierarquizada e a hipótese aqui desenvolvida é que a sub. representação das mulheres se agrava conforme nos aproximamos de suas posições

\footnotetext{
${ }^{1} \mathrm{O}$ artigo apresenta discussões e dados da pesquisa "Determinantes de gênero, visibilidade midiática e carreira política no Brasil", financiada pelo CNPq (editais $n^{\circ} 45 / 2005$ e $n^{\circ} 61 / 2005$ ) e pela FAP.DF (edital n 8/2008) e coordenada por Luis Felipe Miguel.
} 
MIGUEL, L. F.; BIROLI, F. Mídia e representação política feminina...

centrais - e que os meios de comunicação de massa tanto refletem essa desigualdade quanto a promovem. Ao vincular visibilidade midiática e ação política, a pesquisa dota a discussão de um modelo mais complexo e mais apropriado para entender a dinâmica política atual, propondo que se entenda a mídia como uma esfera de representação política, como será discutido na primeira seção deste artigo.

A segunda seção do artigo apresenta uma breve discussão sobre o problema da representação feminina. Nela, explicitamos a abordagem assumida pela pesquisa, respondendo à questão: a que se deve a preocupação com a presença de mulheres na mídia e no Parlamento, assim como o foco analítico nas posições que, uma vez presentes, elas ocupam nos dois campos? E ainda, remetendo a um problema discutido em estudos voltados para a questão da representação política de indivíduos e grupos: a presença ou ausência de mulheres, nos noticiários e no Congresso Nacional, está relacionada ao tratamento menos ou mais adequado de questões que concernem às experiências das mulheres e as preocupam?

As hipóteses que orientam a pesquisa referem-se, de modo central, à questão da articulação entre os campos da mídia e da política e às formas assumidas pela presença feminina nas duas esferas, resultantes, ao mesmo tempo, de constrangimentos que restringem a entrada e atuação das mulheres na esfera política e das escolhas possíveis em meio a esses constrangimentos e restrições que Ihes são impostos. De maneira mais específica, as hipóteses indicam: (1) que existe uma correlação entre a presença, menos ou mais plural, de grupos e indivíduos na mídia e sua presença e atuação em diferentes esferas da vida em sociedade, com destaque para o campo político; (2) que a maneira pela qual a mídia representa (ou deixa de representar) a diversidade social e a pluralidade de interesses presentes na sociedade tem efeitos sobre a dinâmica de representação política; e, por fim, (3) que a mídia deve ser entendida como esfera de representação política - o local onde se manifestam as vozes que representam as diferentes posições no debate público -, como esfera privilegiada de produção das formas de reconhecimento que constituem o capital simbólico e de confirmação ou refutação das hierarquias presentes na sociedade e, mais especificamente, no campo político. Essas primeiras hipóteses estão discutidas ao longo das duas primeiras seções deste artigo.

Duas hipóteses específicas introduzem de modo mais direto a variável gênero e a questão da representação política de mulheres. São elas: (4) a presença e a ausência de mulheres no noticiário político estão relacionadas às especializações e assimetrias existentes no campo político, tal como é configurado atualmente; e (5) os estereótipos de gênero presentes no noticiário político constrangem a ação política das mulheres, na medida em que confirmam e 
reforçam tais especializações e assimetrias. Essas hipóteses estão discutidas na terceira seção deste artigo, onde também está indicada sua correspondência com resultados preliminares da pesquisa empírica.

A pesquisa empírica realizada para testar as hipóteses indicadas consistiu em análises do noticiário político e da atuação de mulheres na esfera política. No que diz respeito ao primeiro eixo, o noticiário político tem sido acompanhado em diferentes veículos de comunicação - os telejornais Jornal Nacional, Jornal da Band e SBT Brasil e as revistas semanais Veja, Época e Carta Capital - em três diferentes períodos, ao longo dos anos de 2006 e 2007. No que diz respeito ao segundo eixo, a pesquisa faz o mapeamento da atuação das deputadas federais na $51^{\mathrm{a}}$ e $52^{\mathrm{a}}$ legislaturas (1999 a 2006) por meio da análise dos discursos proferidos, das proposições apresentadas e da participação em comissões.

Nos dois casos, a pesquisa empírica vem confirmando as hipóteses relativas às restrições à participação e ocupação de posições centrais pelas mulheres na política ${ }^{2}$. O noticiário confirma os limites atualmente existentes para a participação feminina na política, reforçando-os na medida em que os apresenta como a configuração "natural" das relações entre os sexos, com uma presença acentuada dos homens na vida pública, sobretudo nos papéis e áreas de maior relevância, tendo como contraponto uma presença mais acentuada das mulheres em questões ligadas ao cotidiano, à vida familiar e privada. Na política, o percentual reduzido de participação feminina ganha ainda um outro filtro: pode-se observar que, uma vez eleitas, as mulheres atuam menos em áreas e temas tidos como de maior relevância (tratando-se da configuração atual do campo, com seus centros e margens), enquanto os homens estão mais presentes justamente nas áreas e temas que mais contribuem para a promoção de sua carreira política - o que tem como um de seus elementos a visibilidade na mídia.

Observa-se, assim, uma dupla correlação entre a visibilidade na mídia e as hierarquias do campo político. O destaque na mídia é correlato ao destaque no campo político e, além disso, os mecanismos de hieraquização da política . vinculados ao prestígio diferenciado que se concede a trajetórias, cargos e temáticas - guardam correlação com os padrões de visibilidade nos meios de comunicação. A pesquisa defende, a partir da abordagem teórica assumida e dos resultados preliminares das análises empíricas, que as formas de representação do campo político na mídia têm como um de seus elementos significantes uma representação sobre a atuação política de mulheres e sobre as relações de gênero que tende a reforçar (e, no limite, a naturalizar) as posições e estereótipos vigentes,

2 Resultados ainda iniciais do esforço de pesquisa podem ser conferidos em papers, monografias e dissertações vinculados ao projeto: MIGUEL, OHIRA, FEITOSA e CAMPOS (2006), MIGUEL e BIROLI (2007, 2008), FEITOSA (2007), MIGUEL e FEITOSA (2008), BIROLI (2008), BIROLI e MELLO (2008), ANDRADE (2008), MÁXIMO (2008) e SANTOS (2007). 
MIGUEL, L. F.; BIROLI, F. Mídia e representação política feminina...

confirmando e contribuindo para a manutenção da sub-representação e marginalização das mulheres na política.

\section{A mídia como esfera de representação política}

Em que pese a polêmica sobre o conceito, a percepção amplamente dominante sobre a representação política tende a reduzi-la à delegação do poder decisório. O representante é aquele que decide em nome dos outros, tendo recebido este direito por algum processo de transferência, via de regra a eleição. É a visão que funda a redução dos problemas da representação à mecânica eleitoral e às formas da produção da responsividade dos eleitos às preferências de seus constituintes.

No entanto, a tomada de decisões não esgota a atividade de representação política. Ela é a etapa final de um processo que inclui, notadamente, a discussão pública sobre as questões de interesse coletivo - o que inclui a transmissão de informações, a apresentação de argumentos e a exposição de alternativas, com impacto fundamental sobre a constituição da agenda e a formação das preferências. Em sociedades complexas como as nossas, tal discussão não se resume aos debates no parlamento, levados a cabo pelos representantes formais. Ela ocorre em diversos espaços sociais, que influenciam, de diferentes maneiras e em graus diferenciados, a esfera da decisão política corporificada nos poderes institucionais.

Mas é importante entender que as esferas de produção da "opinião pública", embora fluidas e não formalizadas, estão longe de ser igualitárias. Na obra em que define sua compreensão madura da esfera pública, Habermas divide-a em três tipos: uma esfera pública "episódica", de encontros na rua ou em bares e cafés; uma esfera pública de "presença organizada", formada, por exemplo, pelo público de espetáculos ou pelos integrantes de associações; e uma esfera pública "abstrata", produzida pelos meios de comunicação de massa (HABERMAS, 1997, vol. 2, p. 107). Os três tipos, porém, mantêm relações assimétricas entre si. A esfera abstrata possui uma centralidade que as outras não possuem. Sensibilizá-la é uma das tarefas necessárias aos agentes das outras esferas, se têm a ambição de influenciar o processo de tomada de decisões.

Habermas não nega a centralidade dos meios de comunicação de massa, mas, no registro otimista que caracteriza sua obra mais recente, observa que, "apesar da diminuta complexidade organizacional, da fraca capacidade de ação e das desvantagens estruturais, eles [os atores da sociedade civil] têm a chance de inverter a direção do fluxo convencional da comunicação na esfera pública e no 
sistema político" (HABERMAS, 1997, vol. 2, p. 115). Sem dúvida. Mas o reconhecimento dessa possibilidade e de suas eventuais efetivações não pode levar a negar o fato de que o debate público, no qual a opinião pública se forma e se expressa, ocorre sobretudo em canais privilegiados, que são os meios massivos de comunicação.

Justamente por isso, é insustentável o modelo estilizado de Habermas para o funcionamento das democracias liberais, no qual a opinião pública informal gera "influência", que se transforma em "poder comunicativo" através de eleições, metamorfoseando-se em "poder administrativo" através da legislação (HABERMAS, 1997, vol. 1, cap. IV; para uma crítica, ver DRYZEK, 2000, p.25-6). Na posição de operadores cruciais do debate público, os meios de comunicação de massa não podem ser dissolvidos em meio à esfera pública plural como um todo, tampouco se pode entender sua influência como limitada ao processo de formação das preferências eleitorais. E, ao contrário do que ocorre nos outros tipos de esfera pública indicados por Habermas, o acesso à mídia é limitado. Ainda que os veículos que a formam sejam inúmeros, alguns poucos, por sua penetração e influência, formam o núcleo de sua influência social. Aqueles que conquistam acesso a tais meios podem ser entendidos como porta-vozes de grupos sociais, isto é, como representantes políticos.

Dito de outra forma, se é razoável entender a representação política como englobando outras dimensões além da transferência de poder decisório formal, a mídia de massa deve ser percebida como sendo um espaço de representação (MIGUEL, 2003). Nós somos representados por aqueles que, em nosso nome, tomam decisões nos três poderes, mas vemos também nossos interesses, opiniões e perspectivas serem representados nos discursos presentes nos espaços de debate público. Trata-se de uma outra forma de representação, informal, difusa, imprecisa, que depende de adesões por vezes pontuais e revogáveis a qualquer momento, mas nem por isso menos importante no processo público de formulação das decisões. Temos que estar representados porque temos pouca possibilidade de intervir de forma direta e eficaz no debate. $E$, tanto quanto ou até mais do que na representação formal, ruídos e viéses podem comprometer a representatividade nesta instância.

É possível avançar agora para outro aspecto da discussão. A centralidade da mídia no jogo político - o fato de que a política hoje ocorre em um ambiente constituído pelos meios, como disse Gomes (2004) - impacta as formas de atuação e as estratégias dos agentes presentes no campo. Por um lado, a gestão da visibilidade midiática tornou-se um elemento crucial para o avanço das carreiras políticas. Tal gestão é diferenciada de acordo com as pretensões de cada agente e com o conjunto de veículos de comunicação com os quais interage; porém, de maneira geral, é possível dizer que a presença na mídia constitui-se em um 
MIGUEL, L. F.; BIROLI, F. Mídia e representação política feminina...

ingrediente nada desprezível da produção de capital político (MIGUEL, 2002). Por outro lado, a própria pauta de questões relevantes, postas para a deliberação pública, é condicionada em alto grau pela visibilidade de cada questão nos meios massivos. Movimentos sociais, organizações não-governamentais, empresas, grupos de interesse e mesmo partidos, representantes eleitos e a própria administração governamental precisam sensibilizar os meios de comunicação para introduzir e/ou priorizar as questões de seu interesse na agenda pública.

Assim, o peso dos meios de comunicação na determinação da agenda acaba por influenciar os representantes, mesmo em seus próprios fóruns de atuação. Cabe uma breve digressão sobre a relação do parlamentar, ou mesmo do ocupante do poder executivo, com seus constituintes. Do ponto de vista ideal, o vínculo produzido pelo momento da eleição se estende por todo o mandato. De fato, a eleição é tanto o momento da autorização para o exercício do poder quanto da realização da accountability, quando os votantes dão seu veredicto sobre a prestação de contas de seus representantes. A expectativa deste veredicto orienta a ação dos governantes, que não precisam necessariamente se curvar à opinião pública a cada momento, mas devem ser capazes de se justificar diante dela.

$\mathrm{Na}$ prática, sabe-se que são diversos os obstáculos à efetivação da accountability (MIGUEL, 2005). O mais crucial deles está ligado ao fato de que a representação política nas sociedades modernas é multifuncional, ou seja, o mandato concedido, tanto para o executivo quanto para o legislativo e abrange uma quantidade indeterminada de questões. O mandatário tem poder de decisão sobre os temas mais diversos e, tipicamente, ao longo de seu termo, participará de centenas de diferentes processos deliberativos. Os custos de informação para os eleitores se tornam altos, sobretudo porque, por definição (já que se trata da principal condição que sustenta a necessidade dos mecanismos representativos), eles podem dedicar às questões públicas apenas uma pequena parcela de seu tempo e de sua atenção.

A multifuncionalidade da representação implica em múltiplas prestações de conta; o eleitor deve não apenas ser capaz de acompanhá-las - na medida de seu interesse - como dar a cada uma seu justo peso no momento de produzir uma avaliação global do desempenho do governante. Várias fontes concorrem no sentido de prover informações ao público, incluindo-se aí os próprios detentores de mandato, que buscam estabelecer canais para divulgação de suas ações, e organizações da sociedade civil, que divulgam registros de posições referentes aos temas de seu interesse. Mas a mídia ocupa uma posição central, em especial porque - ao contrário de governantes, parlamentares, partidos, movimentos sociais etc. - aparece aos olhos do público como imparcial.

O resultado é que o noticiário dos meios de comunicação acaba por influenciar, em medida considerável, a ação parlamentar. Um parlamentar, bem 
como o chefe de um poder executivo, pode apresentar o projeto que quiser, sobre qualquer tema, e dessa forma submeter o assunto à decisão política, e escolhe livremente os assuntos sobre os quais discursará. Ainda assim, a influência dos meios de comunicação na formulação da agenda é significativa. Há um forte incentivo para que as intervenções e projetos dos governantes sejam ligados aos temas veiculados na mídia, por dois motivos: (i) são os temas de maior visibilidade efetiva, isto é, o político que age a respeito deles mostra-se como mais atuante; e (ii) são os temas de maior visibilidade pessoal potencial, isto é, a intervenção a respeito deles tem maior chance de receber destaque na mídia. Nem sempre os governantes aceitam a imposição da agenda midiática e, muitas vezes, agem no sentido de modificá-la; a atuação de cada um vai depender do grau de vinculação a grupos de interesse definidos e da posição no campo político (MIGUEL, 2002). Mas não se pode ignorar o incentivo presente para políticos em busca de reeleição de aparecer, diante do público, como atuantes e destacados ${ }^{3}$; nem o fato de que a tramitação congressual de questões de pequena visibilidade tende a ser simbólica ou muito lerda, quando não abortada.

Fica claro que participar da elaboração da agenda e participar do debate público são duas faces de uma mesma moeda. Elementos centrais do debate são a composição e a hierarquização da agenda, que incluem tanto a busca por destacar determinado tema quanto, eventualmente, por retirá-lo da discussão. Apresentar os problemas, porém, não é suficiente. Os interlocutores do debate público buscarão também "enquadrá-los", isto é, construir uma narrativa que os explique e, assim, oriente o processo de tomada de decisão. Por vezes, a capacidade de incluir um tema na agenda está dissociada da capacidade de disputar a produção do enquadramento, isto é, a construção de sentido sobre a questão. Formas de ação direta, com recurso à violência ou à desobediência civil, por exemplo, podem ser eficazes para despertar a atenção para um problema, mas os grupos que recorrem a ela perdem legitimidade para serem aceitos como interlocutores públicos, sendo substituídos por outros, mais moderados (GAMSON e MEYER, 1996, pp. 287-9). Na disseminação dos diferentes enquadramentos, uma vez mais, os meios de comunicação de massa ocupam o papel central.

Em síntese, a função de representação política significa tanto tomar decisões em lugar de outros quanto participar da produção da agenda pública e do debate público em nome de outros. Da mesma forma como a primeira dimensão, que é imprescindível em sociedades populosas, extensas e complexas como as contemporâneas, a segunda se impõe na medida em que a participação direta de todos no debate público é inviável. A representatividade dos agentes presentes no debate está, portanto, sujeita a críticas similares às que são endereçadas aos

3 Mais de $40 \%$ do discursos na Câmara dos Deputados fazem menção direta à mídia, em geral como a fonte de informações ou para corroborar os argumentos do orador (MÁXIMO, 2008). 
MIGUEL, L. F.; BIROLI, F. Mídia e representação política feminina...

parlamentos. Se as diferentes vozes presentes na sociedade não se fazem ouvir no debate público - isto é, se o pluralismo político e social desse debate é limitado -, então, há uma distorção que compromete a qualidade da democracia, entendida normativamente como produção autônoma das normas que gerirão o convívio social, por aqueles que a elas estarão submetidos, em condições de igualdade.

Nesse sentido, a compreensão de que os meios de comunicação são uma esfera de representação está diretamente ligada à compreensão de que são um espaço privilegiado de disseminação das diferentes perspectivas e projetos dos grupos em conflito nas sociedades contemporâneas. É evidente que a representação nos fóruns decisórios estabelecidos, caracterizada pela delegação expressa de poder por meio do voto, e a representação no debate público e na formação da agenda, que ocorre em grande medida por intermédio da mídia, ganham aspectos diferentes. Na primeira, a relação entre representantes e representados assume uma feição muito mais formalizada e explícita, mas é também uma relação descontínua, que se cristaliza no momento das eleições, foco em que se concede a autorização e se realiza a accountability. Não é possível imaginar algo tão institucionalizado para a agenda e o debate, na medida em que, entre suas características, estão a fluidez e multiplicidade de espaços em que acontecem - e é bom que seja assim, uma vez que isso indica a possibilidade permanente de reapropriação pela sociedade dos assuntos públicos. Ainda assim, é importante assinalar a necessidade de que os meios de comunicação representem de maneira adequada as diferentes posições presentes na sociedade, incorporando tanto o pluralismo político quanto o social.

Nesse ponto da argumentação, vale avançar um pouco mais na perspectiva assumida na pesquisa sobre a relação entre o campo da mídia e o campo da política, no que diz respeito especificamente à visibilidade e às formas de reconhecimento. A visibilidade nos meios de comunicação de massa é, como já foi dito, um fator fundamental na produção de capital político nas sociedades contemporâneas. Os meios de comunicação são fonte e índice de capital político. A partir de um conjunto de normas e valores que definem o que é noticiável e quem compõe, de formas diferenciadas, a notícia, os meios de comunicação (no caso, especificamente o jornalismo) conferem distinção na medida em que tornam visíveis determinadas personagens. Ao mesmo tempo, a visibilidade é a "constatação", pelo jornalismo, de distinções e competências definidas a partir das normas, valores e hierarquias que regem outros campos, como o da política, e que os meios de comunicação absorvem.

Assim, entende-se que há normas e valores próprios, que orientam a reprodução das hierarquias de posições dentro do campo, no sentido que thes confere Bourdieu (1989) - campos de lutas referentes não apenas aos posicionamentos e status internos a esse espaço de relações, mas também a 
conservação ou transformação dos limites, das margens que estruturam e dão legitimidade às hierarquias reconhecidas e às exclusões sistemáticas. Mas isto não significa assumir que esses processos, regidos por uma "lógica política" ou por uma "lógica midiática", existem de modo independente. Pelo contrário, o que se procura mostrar é justamente a complexidade das imbricações existentes entre eles.

O problema do reconhecimento envolve o da legitimação de formas diferenciadas de inserção e atuação de indivíduos e grupos, menos ou mais reconhecidos como competentes para participar e atuar nas diferentes esferas do mundo social, estabelecendo uma conexão direta entre a mídia, as representações "legítimas" do mundo social e a representação político-institucional. Assume-se, assim, que existe um problema referente à presença, menos ou mais plural, de grupos e indivíduos na mídia em sua correlação com a presença e atuação dos mesmos em diferentes esferas da vida em sociedade, com destaque para o campo político. Nesse sentido, reforçando os aspectos discutidos anteriormente, a maneira como a mídia representa (ou deixa de representar) a diversidade social e a pluralidade de interesses presentes na sociedade tem efeitos sobre a dinâmica de representação política, já que ela é uma esfera privilegiada de produção das formas de reconhecimento que constituem o capital simbólico e de confirmação ou refutação das hierarquias presentes na sociedade. Ainda que sejam reconhecidos os impactos que outros atores possam ter sobre o "fluxo convencional da comunicação na esfera pública e no sistema político", considerando-se mesmo a possibilidade de que sejam capazes, em determinadas circunstâncias, de modificar sua direção (HABERMAS, 1997, vol. II, p. 115), a pesquisa destaca a centralidade e o alcance dos impactos da atuação política da mídia sobre outros âmbitos da esfera pública.

Enfocando nosso problema específico, podemos dizer que as diferenças de gênero, tomadas como diferenças estruturais, têm a mídia como parte de procedimentos que reforçam a estrutura de relações e interações constituída (YOUNG, 1998, p. 93). A mídia compõe esses procedimentos na medida em que difunde visões da realidade social que tendem a confirmar e naturalizar as visões já incorporadas pelos agentes (homens e mulheres) em relação às hierarquias de gênero. As divisões entre público e privado são, nesse sentido, exemplares. A confirmação do "pertencimento" de mulheres e homens a temas e funções vinculados à esfera pública ou à esfera privada, de acordo com as definições e relações historicamente definidas para essas esferas, é uma confirmação prospectiva das hierarquias ligadas à inserção nessas esferas e da divisão do trabalho que implicam. Prospectiva no sentido de que, ao "constatar" a realidade presente, potencializa sua realização no futuro, isto é, sua permanência.

Para Young, as diferenças de gênero são estruturadas por um conjunto de relações e interações que agem em conjunto para produzir possibilidades específicas e excluir outras. São estruturais pelo caráter relativo de permanência 
MIGUEL, L. F.; BIROLI, F. Mídia e representação política feminina...

que têm: "embora o conteúdo específico e detalhado das posições e relações seja frequentemente reinterpretado, desenvolvido e mesmo contestado, as localizações sociais básicas e as relações entre elas tendem a ser reproduzidas" (YOUNG, 1998, p. 95). Como as estruturas sociais são entendidas pela autora como processos que só existem e se concretizam na ação e interação entre as pessoas, a reprodução dessas relações (de dominação) constitui-se como tendência na medida mesmo em que os agentes as incorporam, o que nos permite remeter ao conceito de habitus, a partir de Bourdieu.

Para tratarmos especificamente dos discursos tais como produzidos e difundidos pelo campo midiático, é importante considerar que o habitus primário dos agentes que constituem o campo é marcado pelas relações históricas de dominação e subordinação da mulher, podendo compor, na interação com as disposições específicas do campo, uma visão da mulher como objeto de que se fala. Levantamos, assim, a hipótese de que não se trata, nos noticiários, de uma exclusão simples da mulher, mas da afirmação de perspectivas sobre a mulher, referenciadas pela estrutura de diferenciações de gênero existente, sobrepondo-se a perspectivas de mulheres que potencialmente expusessem traços históricos que tornariam presentes não apenas as perspectivas dos dominados, isto é, perspectivas produzidas pela própria internalização das assimetrias e distinções que constituem a dominação, mas as tensões, confrontos e dissonâncias que essas relações assimétricas implicam.

As formas atuais do campo da mídia ou, em perspectiva que pode ser tomada como correlata, a dinâmica específica de materialização dos discursos (FOUCAULT, 1997), pautada pela repetição e pela incorporação de grades de relevância semelhantes e procedimentos comuns de acesso às fontes de informação, produziria visões do campo político que estão em consonância com as formas atuais de distribuição de capital e reconhecimento naquele campo (como indicam os dados desta pesquisa). Considera-se, assim, que o cotidiano de produção da notícia, as formas de socialização dos jornalistas nas redações e os procedimentos que assumem a repetição como dinâmica privilegiada de produção dos discursos - no caso do jornalismo, destaca-se o recurso dos diversos veículos às mesmas fontes, o papel das assessorias de imprensa, a concorrência entre os veículos e a convivência entre os jornalistas que "cobrem" setores específicos, vinculadas às representações do campo político que predominam, de maneira bastante homogênea, nos noticiários - favorecem a confirmação e naturalização da ordem política vigente, com destaque para as relações de gênero e suas sobreposições às hierarquias e divisões existentes no campo político. 


\section{A sub-representação política das mulheres}

Em muitos países, entre os quais o Brasil, a representação política das mulheres tornou-se um importante tema de discussão nas últimas décadas. Meio século ou mais depois da obtenção do direito de voto pelas mulheres, elas continuavam ocupando uma parcela muito reduzida das posições de poder. Sobretudo a partir dos anos 1970, o movimento feminista obteve êxito em apontar que tal ausência era sinal de um problema - que não se tratava do reflexo de uma pretensa inclinação menor das mulheres para a participação na vida pública, mas do sintoma de uma exclusão, com base estrutural, que devia ser combatida.

A busca por uma presença maior das mulheres nos espaços decisórios se insere em um movimento mais amplo, que identifica, como um dos pontos decisivos de estrangulamento das democracias contemporâneas, a subrepresentação política de determinados grupos sociais. O grupo dos governantes, em relação ao conjunto da população, tende a ser muito mais masculino, muito mais rico, muito mais instruído e muito mais branco - uma observação que vale para o Brasil e para as democracias ocidentais em geral. A expansão da franquia eleitoral, com a incorporação de novos grupos, como as próprias mulheres, os trabalhadores e os analfabetos, à cidadania política, não modificou de forma substantiva a situação. Como observou Anne Phillips (1999, p.35), não basta eliminar as barreiras à inclusão, como no modelo liberal: é necessário incorporar explicitamente os grupos marginalizados no corpo político.

A afirmação da relevância política dos grupos sociais leva a uma ruptura com o individualismo abstrato que marca o pensamento liberal (e, por intermédio dele, o ordenamento constitucional das democracias ocidentais). O rompimento com esta tradição foi embasado teoricamente por uma miríade de pensadores, que, no entanto, oscilam desde a exaltação à diferença de grupo, com o abandono de qualquer perspectiva unificadora, como Iris Marion Young (1990), até a busca de um compromisso com o republicanismo cívico, enfatizando a necessidade de que as pessoas percebam os limites de sua própria posição diante "da comunidade mais ampla à qual todos em última análise pertencemos", que é a posição da própria Anne Phillips (1993, p.106).

Admitido o problema, muitos Estados (primeiro na Europa, em seguida no resto do mundo) passaram a adotar políticas que visavam ampliar a presença dos grupos subalternos nas esferas representativas - em especial as mulheres, já que o sexo biológico se apresenta como uma variável dicotômica e inequívoca, sem ambiguidades, eliminando as polêmicas sobre as fronteiras do grupo a ser beneficiado (como acontece com raça, cor, classe ou renda). As medidas mais importantes envolveram a adoção de cotas eleitorais, implicando a reserva de um determinado contingente de candidaturas femininas. 
MIGUEL, L. F.; BIROLI, F. Mídia e representação política feminina...

Há uma clara ligação entre essa perspectiva e aquilo que, em seu estudo hoje clássico, Hanna Pitkin descreveu (e criticou) como "representação descritiva", que concebe o parlamento como uma espécie de mapa, no qual se vê a imagem perfeita, embora em tamanho reduzido, da sociedade. Com isso, o que os representantes fazem perde importância em relação a quem eles são; e um aspecto valioso da representação política, a accountability dos eleitos para com seus eleitores, é deixado de lado (PITKIN, 1967). Ao defender o que prefere chamar de "política de presença" das críticas de Pitkin e outros, Anne Phillips (1993) admite que ela nasce da desilusão com a accountability esperada dos representantes, que se mostraram incapaz de proteger as minorias.

No Brasil, a principal resposta prática ao problema da sub-representação feminina foi a mudança na legislação eleitoral, que introduziu cotas para candidaturas femininas nos partidos e coligações. Os resultados têm sido, até certo ponto, frustrantes, o que é atribuído tanto às peculiaridades do nosso sistema eleitoral, de representação proporcional em listas abertas (ARAÚJO, 1998, 2001a, 2001b), quanto à tibieza com que a reserva de candidaturas foi introduzida, permitindo que as vagas destinadas às mulheres ficassem em aberto, ampliando o número de candidatos em cada lista, e não obrigando os partidos a destinarem recursos às suas candidatas (MIGUEL, 2008).

A legislação brasileira, assim, não oferece mais do que um estímulo tênue para que mais mulheres concorram às eleições legislativas. Espera-se que, a médio prazo, esse estímulo se reverta numa ampliação expressiva do número de mulheres presentes nos espaços de tomada de decisão. Porém, isso ainda não significa que a igualdade política entre os sexos está pronta para ser alcançada. Ainda que, por exemplo, todos os deputados e deputadas federais sejam formalmente iguais, a prática demonstra que alguns possuem mais prestígio, mais espaço, mais influência do que outros, o que é próprio de um campo, no sentido que Bourdieu empresta ao termo. Assim, da mesma forma que há uma diferença entre concorrer e se eleger, há outra, entre se eleger e alcançar as posições centrais no campo político, isto é, as posições de elevado capital político.

Os dados preliminares da pesquisa mostram que, ao percentual reduzido da presença feminina - nos noticiários e nos parlamentos -, soma-se uma associação entre a presença feminina e determinadas áreas de atuação, o que será discutido, do ponto de vista das hipóteses específicas assumidas pela pesquisa e de alguns dados preliminares, na próxima seção deste artigo. O âmbito considerado "próprio" para a política feminina - questões sociais; questões ligadas à família, à infância e à adolescência; meio-ambiente etc. - é também aquele que menos impulsiona as carreiras políticas e que possui menor visibilidade na cobertura jornalística da política.

Essa diferença, empiricamente constatada, pode ser explicada de diversas 
formas. Uma corrente dentro da teoria feminista afirma que ela indica uma diferença moral entre homens e mulheres, que sustentaria, da forma mais radical (no sentido preciso da palavra), a especificidade da representação política das mulheres. Dar espaço à representação política feminina seria dar voz, nas discussões públicas, a uma outra sensibilidade, que hoje permanece circunscrita à esfera doméstica ${ }^{4}$.

A principal referência, na sustentação dessa postura, é o livro da psicóloga estadunidense Carol Gilligan - In a different voice - um misto de pesquisa empírica e reflexão teórica, baseada, por sua vez, na revisão que a antropóloga Nancy Chodorow fez dos escritos de Freud sobre o impacto psicológico das diferenças anatômicas entre os sexos. Para Freud, a formação do superego estava ligada à clara resolução do conflito edipiano, estimulada pelo medo da castração. 0 processo fica obviamente comprometido no caso das mulheres; por isso, conclui, elas mostrariam "menos sentido de justiça do que os homens" (Freud apud GILLIGAN, 1982, p.7). Chodorow (1978) desloca a discussão; em vez da diferença anatômica, o que interessa é o fato de que as mulheres são as principais responsáveis pelo cuidado com os filhos. Assim, a menina possui um modelo (feminino) presente, a mãe, enquanto o menino possui um modelo (masculino) ausente, o pai. Isto faz com que as características masculinas do menino sejam desenvolvidas na forma de regras abstratas; já a menina desenvolve suas características femininas a partir de relações concretas e emocionais.

O modelo de Chodorow é bem mais complexo do que este resumo; o importante, para a presente discussão, é que ela apresenta o desenvolvimento de duas formas diferentes de relação com o mundo, em vez de apenas dois diferentes estágios da formação da moralidade, um avançado (o masculino) e o outro atrasado (o feminino). As mulheres possuiriam maior sensibilidade para as necessidades alheias, recusando a abordagem fria e impessoal que é própria da abordagem masculina da justiça.

Gilligan recusa o essencialismo em sua abordagem, afirmando que o padrão moral alternativo, que descreve em seu livro, "é caracterizado não por gênero, mas por tema" e que "sua associação com as mulheres é [apenas] uma observação empírica" (GILLIGAN, 1982, p.2). A rigor, portanto, sua preocupação seria alertar para a necessidade de reconhecer a legitimidade do padrão não-dominante de moral, e não especificamente apontar uma singularidade constitutiva das mulheres. Da mesma forma, Chodorow aponta que a reprodução da maternidade - que, na sua teoria, fornece a chave para a construção do papel feminino - ocorre "através de processos psicológicos socialmente induzidos", não sendo "nem um produto da biologia, nem de treinamento intencional” (CHODOROW, 1978, p.7).

4 Uma discussão mais detida desta questão está em Miguel (2001). 
MIGUEL, L. F.; BIROLI, F. Mídia e representação política feminina...

No entanto, a apropriação da obra de Gilligan e de Chodorow por teóricas políticas feministas como Sara Ruddick (1989) e Jean Bethke Elshtain (1981), entre outras, resvalou com frequência para uma postura essencialista. A diferença feminina pode não ser "natural", no sentido de "biológica", mas é vista como fundante da identidade das mulheres, de uma maneira tão elementar que, para todos os efeitos, está naturalizada. Um exemplo expressivo é a introdução do livro de Ruddick, em que ela narra como a experiência da maternidade proporcionou-Ihe a reconciliação com sua identidade feminina - e o passo fundamental nesse processo teria sido o distanciamento em relação à Razão masculina e opressora.

Sob o nome de "política do desvelo" (care politics) ou então de "pensamento maternal", essas autoras afirmam que as mulheres trariam um aporte diferenciado à esfera política, por estarem acostumadas a cuidar dos outros e a velar pelos mais indefesos. Com uma presença feminina mais expressiva nas esferas de poder, haveria o abrandamento do caráter agressivo da atividade política, que é visto como sendo inerentemente masculino. As mulheres trariam para a política uma valorização da solidariedade e da compaixão, além da busca genuína pela paz; áreas hoje desprezadas nos embates políticos, como amparo social, saúde, educação ou meio ambiente, ganhariam atenção renovada ${ }^{5}$.

A corrente leva a crer que a alteração dos padrões de comportamento na política será a decorrência natural da paridade nos foros decisórios. No entanto, a experiência de mulheres no poder revela que a relação entre gênero e "política do desvelo" nada possui de automática. Se, no âmbito parlamentar, as mulheres se ocupam com mais frequência de temas "sociais" do que de hard politics (administração pública, política econômica, relações internacionais), isso ocorre por se tratar do único nicho disponível para elas no campo político (DELPHY, 1994). Assim, o sucesso das políticas que visam a ampliação da presença feminina nos foros de poder traria, como consequência, a destruição desse argumento, na medida em que permitiria que as mulheres disputassem, de forma mais intensa e com maiores possibilidades de êxito, também as áreas que hoje são quase-monopólio dos homens.

É legítimo argumentar que os temas considerados femininos são importantes, talvez até mesmo mais importantes do que os outros; concretamente, porém, são as questões de menor prestígio no campo político, que exigem menor capital simbólico de quem vai tratar delas e alavancam de forma menos expressiva a carreira futura. O discurso da "política maternal" propõe uma alteração da hierarquia de prestígio das atividades políticas, o que merece reflexão, mas, ao mesmo tempo, parece eternizar a divisão do trabalho político, insulando as mulheres em seu nicho próprio e destinando aos homens as tarefas que, ao menos

5 Para um resumo da discussão, com ênfase em sua crítica por outras correntes feministas, ver Mouffe (1992). 
por enquanto, são as mais valorizadas socialmente.

É possível dizer, como se verá na próxima seção, que os meios de comunicação de massa contribuem para o insulamento temático das mulheres na política, na medida em que tendem a dar mais espaço às intervenções de mulheres sobre temas julgados femininos (ver KAHN e GOLDENBERG, 1991; BRADEN, 1996; HELDMAN, CARROLL e OLSON, 2000). Àquelas que fogem à regra, reservam epítetos preconceituosos - basta pensar no "Dama de Ferro", aplicado primeiro a Thatcher, depois a outras líderes políticas que ocuparam cargos considerados próprios de homens (no Brasil, Zélia Cardoso de Mello e, agora, Dilma Rousseff) -, quando não insinuações veladas de que seriam "masculinizadas". Elas são, no entanto, a exceção. Como regra, as mulheres que ingressam na arena política não tardam a perceber o ônus que representa um enfrentamento aos estereótipos de sexo. Os meios de comunicação, o Estado, os partidos e o próprio eleitorado mostram-se mais confortáveis diante de mulheres que correspondem àquilo que se espera delas, e esse é um fator que pesa nas suas chances de êxito eleitoral e político (ver LEEPER, 1991; WITT, PAGET e MATTHEWS, 1994; SMITH e FOX, 2001; FOX e OXLEY, 2003; GORDON, SHAFIE e CRIGLER, 2003; HERRNSON, LAY e STOKES, 2003; DOLAN, 2004).

Vale lembrar, nesse sentido, que os referenciais utilizados para o julgamento de mulheres e homens na política são também diferenciados. Calcados na estrutura de gênero atual, consistem em avaliações que incidem de forma mais direta sobre a vida privada e o trato social no caso das mulheres (a avaliação de sua atividade profissional passa pelo seu maior ou menor ajustamento às regras da polidez feminina e das exigências morais de um certo decoro e dedicação na vida familiar), e sobre a habilidade técnica e competitiva e a "firmeza" de atitudes no caso dos homens. Do mesmo modo, o corpo marca a produção de identidades para as mulheres de maneira muito mais incisiva do que para os homens (BOURDIEU, 1998; YOUNG, 2005).

\section{Gênero, mídia e política: hipóteses de pesquisa e indicações empíricas}

Nesta seção conclusiva, estão discutidas as duas hipóteses específicas e complementares enunciadas na introdução do artigo: (1) a pequena visibilidade de mulheres no noticiário político está relacionada às especializações e assimetrias existentes no campo político, tal como é configurado atualmente; e (2) os estereótipos de gênero presentes no noticiário político constrangem a ação política das mulheres, na medida em que confirmam e reforçam as especializações e assimetrias que fundamentam sua exclusão do campo político ou sua presença em posições de menor centralidade, ampliando os custos simbólicos de uma posição desviante. 
MIGUEL, L. F.; BIROLI, F. Mídia e representação política feminina...

A partir do reconhecimento de que a mídia orienta fortemente o público no que diz respeito aos temas sobre os quais pensar, isto é, o que é relevante e merece atenção (hipótese de agenda setting), a pesquisa observa como esse "o que" é acompanhado de um "quem" que é um misto de designação de competência (muitas vezes autorreferente, isto é, a visibilidade midiática seria capaz de "atestar", ela mesma, a competência daqueles que, por ela, se fazem vistos e ouvidos) e de designação de diferenciação. Homens e mulheres tornam-se visíveis, na mídia, vinculados de maneira diferenciada e assimétrica a campos da vida social e aos temas que perpassam esses campos.

No seu estudo hoje clássico sobre a opinião pública, Walter Lippmann observava que a ação humana "não é baseada em conhecimento direto e seguro, mas nas imagens [do mundo] que cada um constrói ou recebe" (LIPPMANN, 1997, p. 16). Os meios de comunicação são grandes fornecedores destas representações. É claro que eles não formam nossa visão de mundo - diferentes instâncias contribuem para estabelecer os mecanismos de decodificação das mensagens da mídia e, por outro lado, o papel da vivência cotidiana também é significativo. Mas o fato de que o público não absorve de forma mecânica o aporte dos meios de comunicação não o torna irrelevante. A pergunta "como é o mundo tal como a mídia o apresenta a seus receptores?" não esgota a questão da produção das representações do mundo social, mas não é possível prescindir dela.

Para os fins da pesquisa, convém observar que esse mundo é, em primeiro lugar, um mundo muito masculino. Os dados obtidos se referem apenas a uma parcela do material jornalístico, mas são eloquentes: os homens sobrepujam as mulheres no noticiário das revistas e dos telejornais, a razões de 4 para 1 e 3,5 para 1 , respectivamente. Sem que se queira estabelecer qualquer generalização, existem indícios que permitem supor que o quadro não é muito diferente em outros veículos e na programação de entretenimento ${ }^{6}$. São os homens que se colocam na esfera pública, são deles os feitos que merecem ser narrados.

As poucas mulheres presentes nas narrativas do jornalismo estão, além disso, concentradas em áreas específicas - no noticiário de fait-divers, que inclui notadamente a movimentação dos astros do show business, e na cobertura que a imprensa chama de "Cidades" ou "Cotidiano". Ao observarmos estas divisões internas ao noticiário, remetemos ao problema mais geral da divisão entre o público e o privado. Nesse caso, o que está em questão não é o que se torna visível no jornalismo, mas como fatos, discursos, agentes e experiências se tornam públicos, são incorporados ao noticiário, em narrativas e enquadramentos que Ihes dão sentido e valor. Se, em números absolutos, a presença dos homens é sempre maior

6 Mesmo na literatura, espaço considerado mais aberto a perspectivas críticas e desviantes. Por exemplo no romance brasileiro contemporâneo, $62,1 \%$ das personagens (e $71,1 \%$ dos protagonistas) são do sexo masculino (DALCASTAGNË, 2005). 
que a das mulheres, o percentual de mulheres aumenta nas áreas, temas e experiências mais próximas às questões que seriam vinculadas à vida privada e ao cotidiano. Alguns exemplos, nas reportagens, são os cuidados com as crianças de modo geral e, mais especificamente, com a educação dos filhos; o consumo doméstico e os cuidados com o orçamento doméstico, a casa e a família; o trato com o corpo e a aparência física; as "fofocas" ligadas a casamento, romances e aparência física, contribuindo para uma concentração acentuada de mulheres nas categorias "cidades", "fait-divers" e "lições de vida".

Por sua vez, economia e política são territórios masculinos. No noticiário político, que interessa em especial à pesquisa, a presença feminina é ainda menor do que na média - são 8,2 homens para cada mulher nas revistas e 6,1 homens para cada mulher nos telejornais ${ }^{7}$. E muitas das mulheres presentes em reportagens de economia nos telejornais, por exemplo, são donas-de-casa entrevistadas em enquetes sobre consumo. Nas reportagens policiais, também no caso dos telejornais, há diferença na presença como vítima, com maior concentração feminina, e como criminoso ou suspeito e investigador, na imensa maioria homens.

Ao mesmo tempo em que é tão masculino, o noticiário político se mostra relativamente impermeável à presença de pessoas que não pertençam ao universo da política institucional - os três poderes e os partidos. Apenas uma minoria irrisória de reportagens traz integrantes de movimentos sociais, organizações nãogovernamentais ou mesmo de empresas. "Especialistas", como cientistas políticos, economistas ou juristas são ouvidos com certa frequência, em nome de seu saber específico - e as pessoas comuns costumam entrar apenas na condição de "populares", apresentando discursos ilustrativos de uma sensibilidade pouco sofisticada e pouco informada, quando não abertamente folclóricos. A proporção de "populares" entre as mulheres é cerca de cinco vezes maior do que entre os homens.

Assim, a política, tal qual apresentada nos noticiários, é um espaço masculino. É possível argumentar que se trata apenas de um reflexo da organização atual da esfera política, em que as mulheres estão em posição francamente minoritária. No entanto, a afirmação não é estritamente verdadeira: a sub. representação no noticiário jornalístico é mais acentuada do que no campo político; há menos deputadas e senadoras nas revistas e telejornais do que na Câmara e no Senado. Além disso - e mais importante -, as representações veiculadas nos meios de comunicação reforçam as visões de mundo que estabelecem expectativas e

7 Cumpre observar que os dados dos telejornais, ao contrário dos das revistas, se referem apenas ao segundo semestre de 2006 - período eleitoral, portanto, quando a presença de mulheres no noticiário político, ainda que diminuta, foi inflada pela candidatura da senadora Heloísa Helena à presidência da República. 
MIGUEL, L. F.; BIROLI, F. Mídia e representação política feminina...

constrangimentos à ação dos diferentes grupos e indivíduos na sociedade. No caso em foco, a construção da divisão entre uma esfera privada feminina e uma esfera pública masculina faz com que as mulheres na política se vejam na posição de forasteiras, tendo que reafirmar, a cada momento, seu "direito" de estar ali.

Isso ocorre notadamente com as mulheres se colocando com responsáveis pela "importação" das temáticas vinculadas à esfera privada para o espaço da política. A análise de uma amostra de mais de 10 mil discursos pronunciados no plenário da Câmara Federal durante a $51^{\text {a }}$ e a $52^{\mathrm{a}}$ legislaturas (1999 a 2006) mostra uma concentração desproporcional das deputadas nas questões vinculadas a direitos humanos $(15,8 \%$ dos discursos delas, contra $4,9 \%$ dos discursos dos deputados homens) e a família e infância (8,2\% contra 2,7\%). Agrupadas todas as temáticas de teor mais social ou vinculadas à esfera privada (educação, saúde, família, habitação, direitos do consumidor etc.), elas aparecem em 47,1\% dos discursos das mulheres, contra apenas $31,6 \%$ dos homens ${ }^{8}$.

Não se trata de dizer que tais temáticas são menos importantes, em si, do que aquelas mais vinculadas ao núcleo duro da política, como economia, relações internacionais ou administração pública. O importante é perceber que elas possuem menor prestígio no seio do campo político. De fato, os números da pesquisa revelaram que os deputados mais experientes e, sobretudo, aqueles que ocupam posições mais centrais no campo político (aferidas de acordo com cargos exercidos e com a presença nas listagens de "parlamentares mais influentes" elaborada pelo Departamento Intersindical de Assessoria Parlamentar) tendem a se ocupar menos das questões tidas como "femininas". Por outro lado, as (poucas) mulheres que chegaram à elite da Câmara mostram um perfil de preferências temáticas similar ao dos homens (FEITOSA, 2007, p. 54).

Os dados corroboram a percepção de que os estereótipos de gênero impõem constrangimentos à ação das mulheres na política. É possível dizer que esses são impostos também aos homens, que encontrariam dificuldades para escapar ao modelo considerado "masculino". A diferença é que a ação esperada dos homens é aquela que melhor promove a carreira política, ao passo que o comportamento "feminino" contribui para reter as mulheres nas posições mais periféricas do campo.

Ou seja, ao ingressar na vida política, uma mulher deve pesar o quanto vai se conformar às expectativas sobre sua atuação - restringindo-se a áreas de menor prestígio e visibilidade, com menor potencial para agregar capital simbólico - e o quanto vai afrontá-las, sofrendo os ônus vinculados a uma conduta desviante. Tratase de um cálculo bem mais custoso do que aquele ao qual os homens se encontram submetidos. Essas expectativas, vinculadas aos estereótipos de gênero e

8 Os dados completos estão apresentados em Feitosa (2007); ver também Andrade (2008). 
confirmadas cotidianamente pela divisão sexual do trabalho político, num processo de naturalização que colabora para sua perpetuação, estão presentes entre o público (isto é, os eleitores), entre as lideranças políticas e entre as próprias mulheres (ver BOURDIEU, 1998). Também estão presentes nos jornalistas, de ambos os sexos, que produzem o noticiário político'.

O cálculo que as mulheres no campo político devem fazer inclui, como um de seus elementos importantes, a visibilidade na mídia. Trata-se de um processo circular: essa visibilidade tanto produz capital político quanto dele deriva. 0 jornalismo concede mais espaço às mulheres quando elas se encontram próximas de sua esfera tradicional, a dos assuntos privados e a do cuidado com os outros, mas a vinculação a tais temáticas as afasta do núcleo do noticiário político. Observam-se, então, mecanismos de reforço entre mídia e campo político, que obstaculizam em primeiro lugar o ingresso das mulheres e, em seguida, seu progresso na carreira política.

As formas assumidas pela presença de homens e mulheres no noticiário remetem a mecanismos mais amplos por meio dos quais a estrutura atual das divisões e diferenciações de gênero se preserva. Isso implica na observação da correlação entre as divisões de gênero e a compreensão vigente das diferenciações entre o que se entende por público e o que se entende por privado. Essas diferenciações, por sua vez, são investidas de valor, tanto do ponto de vista concreto (um exemplo é a não remuneração ou baixa remuneração do trabalho doméstico) quanto do ponto de vista simbólico (um exemplo, nesse caso, é a pouca visibilidade, nos noticiários, dos problemas relacionados à divisão sexual do trabalho, que implicam em ônus para as mulheres, enquanto ganha visibilidade e realidade uma espécie de representação "pós-feminista" das relações de gênero, em que o sucesso de algumas mulheres, na política ou no mercado, indicaria a existência de relações de gênero mais "justas" no que se refere às oportunidades que estariam abertas a um e a outro sexo).

Os dados preliminares da pesquisa apontam, assim, para algumas dimensões do gênero no noticiário, especialmente nas representações do campo político nele presentes. Os telejornais e revistas semanais analisados (sem diferenças significativas entre eles) reproduzem e mesmo reforçam a especialização da atividade política, que as instituições da democracia representativa levam a cabo. Por um lado, é consagrada a divisão entre políticos profissionais e "espectadores" da política. Têm legitimidade para frequentar o noticiário político aqueles que estão investidos em cargos públicos, sejam eles eletivos ou de confiança; aos outros cabe acompanhar o jogo. Isso fica evidenciado de forma ainda mais clara pela irrelevância dos depoimentos dos "populares", destinados a cumprir

9 A pesquisa mostrou que repórteres do sexo feminino não abrem mais espaço para mulheres em suas reportagens. 
um papel meramente ilustrativo, quando não folclórico, sem que se espere que produzam qualquer colaboração pertinente ao debate que se trava entre os atores políticos legítimos. O fato de que entre os populares a concentração de mulheres seja ampliada em relação a outras formas de presença no noticiário dá nitidez também ao outro aspecto relevante dessas divisões, o de gênero, confirmando a hipótese enunciada. Ao reforçar compreensões tradicionais das divisões entre o público e o privado, assim como uma visão do campo político como espaço masculino - que teria como um de seus princípios de valorização a divisão das competências segundo o sexo -, o noticiário reproduz estereótipos de gênero, ao mesmo tempo em que tem papel ativo na sua naturalização e manutenção.

\section{Referências bibliográficas}

ANDRADE, G. O. Presença da diferença: uma análise da atuação feminina no Congresso Nacional. Brasília. Dissertação de mestrado em Ciência Política. Instituto de Ciência Política da Universidade de Brasília, 2008.

ARAÚJO, C. "Mulheres e representação política: a experiência das cotas no Brasil". Estudos Feministas, Florianópolis, vol. 6, nº 1, p. 71.90, 1998.

"As cotas por sexo para a competição legislativa: o caso brasileiro em comparação com experiências internacionais". Dados, Rio de Janeiro, vol. 44, n 1, p. 155.94, 2001 a.

. "Potencialidades e limites da política de cotas no Brasil". Estudos Feministas, Florianópolis, vol. 9, $n^{\circ} 1$, p. 231-52, 2001b.

BICKFORD, S. The dissonance of democracy: listening, conflict, and citizenship. Ithaca: Cornell University Press, 1996. 
BIROLI, F. Gênero e política no noticiário das revistas semanais brasileiras. Paper apresentado no $32^{\circ}$ Encontro Anual da Anpocs. Caxambu, 27 a 31 de outubro, 2008.

BIROLI, F. e MELLO, J. Gênero e representação política: limites e apostas na atuação das deputadas federais na 52 ${ }^{\mathrm{a}}$ Legislatura (2003-2006). Paper apresentado no VI Encontro da Rede Brasileira de Estudos e Pesquisas Feministas (REDEFEM). Belo Horizonte, 10 a 13 de junho, 2008.

BOURDIEU, P. La distinction: critique sociale du jugement. Paris: Minuit, 1979.

. Questões de sociologia. Rio de Janeiro: Marco Zero, 1983.

. O poder simbólico. Rio de Janeiro: Bertrand Brasil, 1989.

. La domination masculine. Paris: Seuil, 1998.

. Meditações pascalianas. Rio de Janeiro: Bertrand Brasil, 2001.

BRADEN, M. Women politicians and the media. Lexington: University of Kentucky Press, 1996.

CHODOROW, N. The reproduction of mothering. Berkeley: University of California Press, 1978.

DALCASTAGNÈ, R. "A personagem do romance brasileiro contemporâneo: 1990-2004". Estudos de Literatura Brasileira Contemporânea, Brasília, n² 26, p. 13-71, 2005.

DELPHY, C. "Feminismo e recomposição da esquerda". Estudos Feministas, Rio de Janeiro, v. 2, n 1, p. 187-99, 1994. 
DOLAN, K. "The impact of candidate sex on evaluations of candidates for the U.S. House of Representatives". Social Science Quarterly, Houston, v. 85, nº 1, p. 206-17, 2004.

DRYZEK, J. Deliberative democracy and beyond: liberals, critics, contestations. Oxford: Oxford University Press, 2000.

ELSHTAIN, J. B. Public man, private woman: women in social and political thought. Priceton: Princeton University Press, 1981.

FEITOSA, F. Penetras no Clube do Bolinha: a carreira política de mulheres na Câmara dos Deputados. Brasília. Monografia de graduação em Ciência Política. Instituto de Ciência Política da Universidade de Brasília, 2007.

FOUCAULT, M. A arqueologia do saber. Rio de Janeiro: Forense Universitária, 1997.

FOX, R. L. e Z. M. OXLEY. "Gender stereotyping in state executive elections: candidate selection and success". The Journal of Politics, Nashville, v. 65, n 3, p. 833-50, 2003.

GAMSON, W. A. e MEYER, D. S. Framing political opportunity. In: McADAM, D., J. D. McCARTHY e M. N. ZALD (eds.). Comparative perspectives on social movements: political opportunities, mobilizing structures, and cultural framings. Cambridge: Cambridge University Press, 1996.

GILLIGAN, C. In a different voice: psychological theory and woman's development. Cambridge (MA): Harvard University Press, 1982.

GOMES, W. Transformações da política na era dos meios de comunicação de massa. São Paulo: Paulus, 2004.

GORDON, A.; SHAFIE, D. M. e CRIGLER, A. J. "Is negative advertising effective for female candidates? An experiment in voters' uses of gender sterotypes". Press/Politics, Thousand Oaks, v. 8, $n^{\circ} 3$, p. 35-53, 2003. 
HABERMAS, J. Direito e democracia: entre facticidade e validade. Rio de Janeiro: Tempo Brasileiro, 1997.

HELDMAN, C.; CARROLL, S. J. e OLSON, S. Gender differences in print media coverage of presidential candidates: Elizabeth Dole's bid for Republican nomination. Paper apresentado no Encontro Anual da APSA. Washington, 31 de agosto a 3 de setembro, 2000.

HERRNSON, P. S.; LAY, J. C. e STOKES, A. K. “Women running 'as women': candidate gender, campaign issues, and voter targeting strategies". The Journal of Politics, Nashville, v. $65, n^{\circ} 1$, p. 244-55, 2003.

KAHN, K. e GOLDENBERG, E. N.. "Women candidates in the news: an examination of gender differences in U.S. Senate campaign coverage". Public Opinion Quarterly, Chicago, v. 55, n 1 , p. $180-99,1991$

LEEPER, M. S. "The impact of prejudice on female candidates: an experimental look at voter inference". American Politics Quarterly, Thousand Oaks, v. 19, n² 2, p. 248-61, 1991.

LIPPMANN, W. Public opinion. New York: Free Press, 1997.

MÁXIMO, H. A influência da mídia na decisão política: uma outra interface de poder. Brasília. Dissertação de mestrado em Ciência Política. Instituto de Ciência Política da Universidade de Brasília, 2008.

MEYROWITZ, J. No sense of place: the impact of electronic media on social behavior. Oxford: Oxford University Press, 1985.

MIGUEL, L. F. "Política de interesses, política de desvelo: representação e 'singularidade feminina'”. Estudos Feministas, Florianópolis, vol. 9, n 1, p.253-67, 2001. 
"Os meios de comunicação e a prática política". Lua Nova, São Paulo, vol.6, nº 55 , p.155-84, 2002

. "Representação política em 3-D: elementos para uma teoria ampliada da representação política”. Revista Brasileira de Ciências Sociais, São Paulo, n 51, p.123-40, 2003.

"Impasses da accountability: dilemas e alternativas da representação política". Revista de Sociologia e Política, Curitiba, n²5, p.165-78, 2005.

"Political representation and gender in Brazil: the quotas for women and their impact". Bulletin of Latin American Research, Liverpool, vol. 27, n² 2, p.197-214, 2008.

MIGUEL, L. F.; OHIRA, A.; FEITOSA, F. e CAMPOS, L. A. Falas femininas no Congresso: gênero e nichos discursos na Câmara dos Deputados. Paper apresentado no Seminário Internacional Fazendo Gênero 7. Florianópolis, 28 a 30 de agosto, 2006.

MIGUEL, L. F. e BIROLI, F. Gênero e política na mídia brasileira. Paper apresentado no /I Congresso da Associação Brasileira de Pesquisadores de Comunicação e Política (COMPOLÍTICA). Belo Horizonte, 4 a 6 de dezembro, 2007.

"Gênero e política no jornalismo brasileiro". Revista Famecos, Porto Alegre, n³6, p.24-39, 2008

MIGUEL, L. F. e FEITOSA, F. Representação política e gênero: uma análise a partir dos discursos na Câmara dos Deputados. Paper apresentado no $6^{\circ}$ Encontro da Associação Brasileira de Ciência Política (ABCP). Campinas, 29 de julho a $1^{\circ}$ de agosto, 2008.

MOUFFE, C. Feminism, citizenship and radical democratic politics. In: BUTLER, J. e SCOTT, J. W. (eds.). Feminists theorize the political. London: Routledge, 1992. 
OKIN, S. "Gênero, público e privado". Estudos Feministas, Florianópolis, no prelo, 2008.

PHILLIPS, A. Must feminists give up on liberal democracy? In: HELD, D. (org.). Prospects for democracy: North, South, East, West. Stanford: Stanford University Press, 1993.

.Which equalities matter? Cambridge: Polity, 1999.

PITKIN, H. F. The concept of representation. Berkeley: University of California Press, 1967.

RUDDICK, S. Maternal thinking: toward a politics of peace. Boston: Beacon Press, 1989.

SANTOS, J. M. Gênero, representação e instituições. Brasília. Dissertação de mestrado em Ciência Política. Instituto de Ciência Política da Universidade de Brasília, 2007.

SMITH. E. R. A. N. e R. L. FOX. "The electoral fortunes of women candidates for Congress". Political Research Quarterly, Sacramento, vol. 54, nº. 1, p. 205-21, 2001.

THOMPSON, J. B. Ideologia e cultura moderna: teoria social crítica na era dos meios de comunicação de massa. Petrópolis: Vozes, 1995.

WITT, L., PAGET, K. M. e MATTHEWS, G. Running as a woman. New York: The Free Press, 1994.

YOUNG, I. M. Justice and the politics of difference. Princeton: Princeton University Press, 1990. 
. Polity and group difference: a critique of the ideal of universal citizenship. In: PHILLIPS, A. (ed.). Feminism and politics. Oxford: Oxford University Press, 1998.

. On female body experience. Oxford: Oxford University Press, 2005.

Luis Felipe Miguel-Ifelipe@unb.br

Flávia Biroli · fbiroli@terra.com.br

Recebido para publicação em julho de 2008.

Aprovado para publicação em outubro de 2008. 